University of Windsor

Scholarship at UWindsor

2010

\title{
Full-Court Quest: The Girls from Fort Shaw Indian School, Basketball Champions of the World
}

Victoria Paraschak

University of Windsor

Follow this and additional works at: https://scholar.uwindsor.ca/humankineticspub

Part of the Kinesiology Commons

\section{Recommended Citation}

Paraschak, Victoria. (2010). Full-Court Quest: The Girls from Fort Shaw Indian School, Basketball Champions of the World. Sport History Review, 41 (1), 81-90.

https://scholar.uwindsor.ca/humankineticspub/15

This Book Review is brought to you for free and open access by the Faculty of Human Kinetics at Scholarship at UWindsor. It has been accepted for inclusion in Human Kinetics Publications by an authorized administrator of Scholarship at UWindsor. For more information, please contact scholarship@uwindsor.ca. 


\section{Full-Court Quest: The Girls from Fort Shaw Indian School, Basketball Champions of the World}

By Linda Peavy and Ursula Smith. Published in 2008 by the University of Oklahoma Press (496 pp., 42 B\&W illustrations, index; \$29.95 U.S.).

Reviewed by Victoria Paraschak, University of Windsor.

Rarely does an academically grounded, detailed, and lengthy story captivate a reader the way that Full-Court Quest did for me. Linda Peavy and Ursula Smith spent over ten productive years researching and writing this "(hi)story" about ten exceptional female athletes from the Fort Shaw Indian Boarding School. The authors begin this story with Pea-boa, a Bannock woman, skillfully and enthusiastically playing "double ball," a traditional ball game in her culture. Her exuberance in play foreshadows the approach taken by other women, including her granddaughter Minnie Burton, who would build on their traditional love of ball games to embrace a new activity - basketball. These athletes demonstrated hard work in practice and love of the game over several years, culminating in their success at the St. Louis World's Fair in 1904, where they became the "Basketball Champions of the World." That story, so effectively summarized and problematized in the epilogue, lies at the heart of this readable and engaging book.

The process by which this book was written is central to its successful outcome. The authors' extensively researched history (sixty-nine pages of notes) has drawn on government records and reports, newspapers, unpublished documents, and sixty-seven interviews, which were then contextualized within academic sources addressing that time period. This information provided the bricks upon which the "story" was then crafted. I never felt that this was a story about the team-it was their story, told in a way that reinforced the choices these women (and those around them) were making.

As an academic interested in learning and communicating about the lives and accomplishments of Aboriginal athletes, I was attentive to both the story itself, and the way the story was told. At first I was engaged in the story but wondered how the authors could have accurately known such minute details about the way things happened. I began to check notes, and realized they were "composing" particular details, at times, by extrapolating from broader information they had collected surrounding the event. I became intrigued by the way they were able to construct an engaging, detailed historical account by going beyond statements of fact known through the data, to imaginations of fact grounded in the data and in the personalities they had come to know through their interviews. I was reminded of Brenda Zeman's similarly engaging 1988 docu-fictional approach for To Run with Longboat: Twelve Stories of Indian Athletes in Canada. Recognizing that historians, in the end, all construct "stories" about the past, which is all we can do given the limited data available, I have come to measure good history in part by similitude - that is, the degree to which the account seems to resemble, or resonate 
with, lived experiences. I expect that the basketball-playing background of both authors, combined with their immersion in details from archival records and the stories of descendents, along with their sophisticated ability to tell a great story, all combined to produce this engaging and academically satisfying book

The authors effectively contextualized this story within the colonial conditions facing young Aboriginal students, who for years were removed from their families and relocated to boarding schools to learn how to be "successful" in White society. Peavy and Smith also wove in the sexist realities facing women at that time, including the absence of female athletes at the 1904 Olympics (except for archers), in part (and conveniently) because women athletes "did not want" to compete in public at that time (p. 312). Ironically, they point out, this women's basketball team had to play an intrasquad game "in front of thousands who flocked to Francis Field to observe the fair's 'primitives' engage in that bizarre and racist spectacle known as the Anthropology Days games" (p. 344) to receive the silver trophy awarded to all winning athletes at the 1904 Olympics.

Peavy and Smith have found a way to tell us an important story — of these exceptional, talented female Aboriginal athletes at a particular time in American history-in a fashion that will appeal equally to scholars of American history, basketball history, and Aboriginal peoples' history; to sociologists concerned about race and gender relations; and to members of the public looking for a great read about an amazing story at the turn of the twentieth century. The authors, most importantly, provide the descendents of these very talented athletes with a story about their elders' accomplishments and life at the Fort Shaw Indian Boarding School that shows they were at the forefront of women's sport-role models-who truly and for many reasons deserved the title "basketball champions of the world."

\section{Football with the Foe: Danish Sport under the Swastika}

By Hans Bonde. Published in 2008 by the University Press of Southern Denmark (272 pp., 46 illustrations; hard cover [in the United States, distributed via www. isbs.com]), \$31.00 U.S.).

Reviewed by Arnd Krüger, Georg-August University Göttingen.

Seventy years ago, on 1 September 1939, Germany started the Second World War by invading Poland. At the same time, Germany's neighbor to the north, the small Kingdom of Denmark, declared its neutrality (just as did adjacent Sweden and Norway). On 9 April 1940, Germany demanded Denmark's unconditional surrender, promising territorial integrity and political independence in case of acceptance at the same time. Denmark consented placing itself into the gray zone between the fiction of neutrality and the reality of a colony. Some Danes were happy, after all they were now part of the "Aryan master race," and some resented losing most of their democratic rights, but collaboration seemed to be a much better choice than a war that could only be lost and would have brought casualties and suffering to the majority of the Danish people.

How far should such collaboration go? This was the question that worried every Dane. In recent years, there has been a revival of interest in this question in 
Denmark, as the younger generation no longer accepted the myth that collaboration and acquiescence offered the only chance Denmark had to survive. In the first three years after the Nazi takeover, collaboration was strong. As soon as the German Army started to lose ground in North Africa and in the Soviet Union, when it became plausible that Germany would not win the War, Danish resistance became stronger and collaboration weaker. When finally Danish Jews were rounded up to be deported to concentration camps, the majority of Danish Jews could flee to Sweden with the help of many Danes in and outside a growing resistance movement.

Every Dane had to decide for him- or herself how far collaboration should go in every walk of life under the Swastika. In sports, many ordinary people were confronted with the problem. In professional sports, such as boxing and cycling, Germany provided well-paid engagements that gave a livelihood-similarly, Danish farmers gladly exported their surplus to hungry Germany. The situation in amateur sports was even more complex: If you followed the theory that sport and politics should not mix, you did something very political when you played football with the oppressor. Every athlete, every club, and every sport federation had to make the daily decision: Where are the limits of collaboration?

This is the question that Danish sport historian Hans Bonde tries to answer in his skillful book. Norway, occupied by Germany in 1940, had a strong resistance movement, whereas Denmark had one only in the latest stages of the war. The Norwegian sports movement was split: The grass roots kept a greater distance with Germany than did the Danish, while the "official" sector willingly played into the hands of the Nazi government. Bonde systematically questions the wisdom of the Danish sports establishment to continue with their sporting relations as if nothing much had happened. In this, Danish sport was not alone. Western democratic nations continued and even developed their sporting relations with Germany after the Nazi takeover in 1933, with the Olympic Games of 1936 being a fine example of the Nazi propaganda success in sports. But once the war had started, German sporting relations were reduced to the neutral, the occupied, and the other fascist nations.

Bonde covers the span from the fascination for Nazi sports after 1933 all the way into the years after the war in order to analyze how the Danes themselves dealt with their collaborators. He uses mainly the archival material of the Danish Sports Federation (DIF), which, however, let many of the separate sports associations decide for themselves. The book therefore is not only about football, but also deals with ten sports with fine differentiations. But what do you find in the minutes of meetings when you are not sure whether people in your midst are not secretly passing on information to the Nazis?

The book is at its best when it deals with openly political issues. As Denmark was torn between the really neutral Swedish sports and the Nazi-dominated Norwegian sports, the political discussions inside the DIF were most pertinent when international relations were on the agenda. As Nazi Germany planned to have an Axis-dominated European sports federation with as many member states as possible, Denmark was part of the international discussions. Bonde shows how the Danish authorities tried to avoid alienating Swedes and Germans alike, making their decisions dependent on the political situation of the day. The German sports leaders Carl Diem and Karl Ritter von Halt, who had played an important role in German and international sports prior to the Nazi era, but also thereafter, are portrayed as willing tools of the Nazi government. It also becomes obvious that the political 
relations of the sports organizations depend to a large extent on the previous personal relations of the acting personnel. The better people knew each other before the war, the more personal trust there was, and the easier it was to understand the potentially dangerous positions administrators were in during the war.

Bonde's focus is on the instrumentalization of sport for political purposes by the Nazis and their Danish followers. The book is not on the everyday experience of the sporting community, but on the concepts and plans of the Nazis. It focuses neither on different individuals nor on the culture of the manifold sports clubs. In this, the cultural turn has not reached the book yet. In the case of Werner Seelenbinder, an internationally successful German wrestler, who was later murdered in a German concentration camp as a stout communist, Bonde accepts that collaboration with the Nazis could mean working against them at the same time. If Bonde accepts this in such a blatant case, why not in less obvious ones in Denmark? People have used sports not only in the way that they were told to, but also in any way they pleased. When Bonde describes the situation of some of the Danish top athletes-such as swimmer Jenny Kammersgaard-in their complex situation, he is at his best.

As far as Hans Bonde's book goes, it is a very good book. It represents the first thorough attempt to analyze the situation of Danish sport during the Second World War. By looking mainly at the macropolitical side of the picture, it leaves out many of the complex elements that are particular to the sports scene. On the basis of this book, more detailed analyses will now be easier-but need to be done.

\section{Coast to Coast: Hockey in Canada to the Second World War}

Edited by John Chi-Kit Wong. Published in 2009 by the University of Toronto Press (288 pp.; cloth, \$70.00 / paper, \$29.95).

Reviewed by Russell Field, University of Manitoba.

In the past decade, sport historians in both Canada and the United States have embraced the study of ice hockey. Two scholarly meetings at St. Mary's University in Halifax were followed by three more conferences between 2004 and 2010, to which have been added two new edited collections. Canada's Game: Hockey and Identity emerged from one of these conferences, whereas the second is the result of historian John Chi-Kit Wong's efforts to delve into the Canadian history of the game: Coast to Coast. (Full disclosure: the former title includes a chapter from the reviewer, who in turn declined an invitation to contribute a chapter to the volume under consideration here.)

These inquiries have paid particular attention to nationalist discourses and issues of identity formation. One of the dominant narratives in the history of Canadian physical activity has been the "making" of organized sport in the dominant political, economic, and cultural centers of the nineteenth century (primarily Montreal and Toronto) and the subsequent dissemination of the amateur sport ethos to the hinterlands. Coast to Coast adds nuance to this focus on the urban heartland. John Matthew Barlow profiles the hockey team of Montreal's Shamrock Club. Typically held up as symbols of the working classes playing within boundaries established by middle-class amateur sportsmen, the Shamrocks are re-imagined 
by Barlow as a team of Irish-Canadian working-class men at the intersection of class, gender, and ethno-religious identities. Wong meanwhile writes the history of boomtown Vancouver alongside the beginnings of professional hockey in the city during the early twentieth century. Yet, in this context, entrepreneurs hoping to develop a market for commercial hockey also worked to develop an amateur tradition in the sport. Such a comingling of sporting ideologies would have been unlikely, perhaps unimaginable in Montreal's more established amateurist culture.

But it is Coast to Coast's contributions to our understanding of hockey in the margins that is most valuable. Hockey at the community and rural level are the subject of chapters from Daniel MacDonald, about hockey leagues in the industrial towns of interwar Cape Breton, and Robert Kossuth, on the development of the game in rural southern Alberta. Additional emphasis is placed on the role of hockey in the construction of gender identities. Stacy Lorenz and Geraint Osborne examine the media coverage of the 1907 games between the Ottawa Silver Seven and Montreal Wanderers, a case study that highlights the ways in which the press accounts sought to construct notions of middle-class masculine respectability while accounting for the violent play occurring on the ice. Carly Adams continues her work on women's sport in the interwar years with a profile of the Ladies Ontario Hockey Association, one of the earliest attempts at administration by Canadian female sport leaders during first-wave feminism. Kossuth also contextualizes the prairie experience by discussing women's hockey in turn-of-the-century southern Alberta.

Despite shining a light on the periphery, the center is never very far from view in Coast to Coast. A number of contributors make explicit the importance in the far reaches of the Dominion of displaying a quality of play equal to that of central Canada. But was this a material or imagined "center?" To what degree was the east-west nature of this axis imposed on the game by nationalist (often commercial) interests? Wong highlights the symbolic importance of the Vancouver Millionaires defeating Ottawa for the Stanley Cup — a vestige of vice-regal attempts at nation building -in 1915. A year later, however, commercial exigencies took precedence over national ones, and Vancouver was competing in a league whose four teams included squads in Seattle and Portland. Such north-south pressures are largely unexplored in this collection. With chapters organized geographically, writing the history of Canadian hockey from east to west, Coast to Coast risks reproducing the east-west nationalist imperative it hopes to interrogate.

Coast to Coast broadens rather than deepens our understanding of hockey's cultural significance in Canada. Kossuth, for example, justifiably argues that the history of hockey must engage with the history of "others" and "search the periphery of sport in smaller communities" (p. 203), yet concludes by noting that his examination of hockey in rural southern Alberta "does not suggest that what took place during the late 1800 s and early 1900s was dramatically different from the state of the sport elsewhere in Canada" (p. 216). Moreover, the introductory "proem" acknowledges the collection's important omissions (francophone, first nations) to any attempt at sketching out hockey's "national" importance, but these are still significant absences-and an exploration of hockey's importance in Canada's turn-of-the-century immigrant communities also still awaits. Perhaps a fuller introduction or an afterword could have drawn out overarching themes, but this is not to underrate the value of Coast to Coast. Providing local context to national narratives allows for a greater appreciation of the processes of adoption and adaptation, consent and resistance. 


\section{India and the Olympics}

By Boria Majumdar and Nalin Mehta. Published in 2009 by Routledge (528 pp.; hardcover, \$120.95 Canadian).

Reviewed by Toby C. Rider, University of Western Ontario.

During my childhood in England, the summer sport was cricket. I knew little of sport in India, except that roughly every three years, the Indian cricket team played England and I got the rare chance to watch some of the finest batsmen I have ever seen. Of course, there was more to sport in India than my narrow perspective grasped, and the authors of India and the Olympics argue that "the story of Indian cricket cannot pass as the story of Indian sport" (p. 7). But still, India and the Olympics is not a topic for a book that leaps to mind, especially not a topic that warrants over five hundred pages. As the authors note, India has accrued only fifteen medals at the Olympics, and not until the 2008 Beijing Games did an Indian athlete win an individual gold. This meager harvest has not discouraged Boria Majumdar and Nalin Mehta, who have written the first detailed history of India's involvement and participation in the Olympic Movement.

The authors attest that sport is, and has been, a central means for fashioning and experiencing national identity in India. This is particularly important when set against the divisive regionalism and factionalism of Indian politics. Sport, it is argued, although stricken by the same problems, can at least claim universal popularity with the Indian people. The Olympics provide a window for the authors to view Indian sport and the internal politics that have mostly obstructed, cleaved, and restricted Indian sporting success. Through all this, the authors are deeply cognizant of the part sport has played in forging an Indian national identity, especially in India's postcolonial times.

In the early chapters, Majumdar and Mehta discuss the unifying and socializing nature of sport in the British Empire, and the impact of the YMCA on the development of sport in India. Without doubt, however, the book is about one Olympic sport rather than many, that being the Indian field hockey experience. They explain that during India's colonial years, it was hockey that emerged as an expression of Indian national identity, not cricket. The first Indian hockey team was sent to the Olympics in 1920. Thus began the rise of India as an international hockey leader, confirmed with a team gold medal at Amsterdam in 1928, a feat that was repeated at each Olympic festival until 1956. Throughout this supreme run of success, the authors claim that the hockey team won in spite of the regional politics that split the Indian Hockey Federation (IHF). As other nations improved, however, the failure of the IHF to offer unified leadership crippled the development of Indian hockey. By the 1970s, team performance declined sharply. Without government help or competent administration, hockey, like other Olympic sport organizations in India, had failed. The same problems appear to have blighted the Indian Olympic Association (IOA), which has served to satisfy the needs of its administrators, rather than athletes. 
Beyond hockey, the book deals with India's involvement and staging of the first International Olympic Committee (IOC)-sanctioned Asian Games in Delhi in 1951. A lack of government financial backing for the Games did not prevent this event from signaling the end of the colonial era, and the beginning of a new independent identity after British rule was rescinded in 1947. A chapter on India's hosting of the 1982 Asiad offers a different view of government involvement in sport. The Games provided a way for Indira Gandhi to restore western confidence in her leadership. It is argued that the 1982 Asiad was also a turning point in Indian television, with a national network established to broadcast the event in color, projecting to the world that India was a modern nation. It also heralded the beginning of India's eventual saturation with satellite networks. Crucially, it was cricket that took advantage of the new media after the national team's victory at the 1983 Cricket World Cup. With this, conclude the authors, Olympic sport in India missed its greatest opportunity.

It is a long book by Olympic standards and, in the reviewer's opinion, unjustifiably long. Although a large portion of the five hundred or so pages are filled with an impressive statistical appendix on Indian participation at the Olympics, over three hundred are dedicated to the task at hand. After two hundred pages, the text takes a huge digression. The reader is given an in-depth chapter on the growth of cricket on the back of satellite television. The point is that cricket subsumed all other sport in India. It is a fair and well-articulated argument, but it is made in a depth that betrays the subject of the book, and the aim of the authors to refocus the attention of the reader away from cricket.

The book is based on considerable research at the IOC archives in Lausanne, which has greatly enriched the study, particularly with regard to the colonial years of the IOA. A large amount of research in newspapers forms the basis for the chapters on hockey. The authors are not specialists in the field of Olympic studies. Majumdar has published widely on Indian cricket, while Mehta has written on the influence of satellite television on Indian culture. This does not always need to be a disadvantage, but in this case, there is an absence of broader Olympic contextual history in the narrative and the notes. In fairness, the authors deal with the Nazi Olympics in a limited manner, and the part played by the Indian IOC member, G. D. Sondhi, in the GANEFO episode. This apart, there seems to be a detachment between the Indian Olympic experience and the evolution of the IOC and its flagship festival, the Olympic Games. For example, chapter two deals with the disunity between the IOA and Indian sports organizations during the early colonial years. There are over a dozen letters quoted in the chapter from the IOC archives, but all the letters are from Indian officials to IOC presidents or international federations. There are no letters going the other way. It would have been interesting to have learned what the IOC thought about the infighting in India, or, better still, what the British IOC members thought of it all.

These complaints aside, the authors have put together a well-researched and very readable book. It is recommended as an excellent means to understand the troubled history of Indian sport, and offers a fresh way to look at the Olympics as experienced by the world's largest democracy. 


\section{The Philadelphia Phillies}

By Frederick G. Lieb and Stan Baumgartner. Published in 2009 by Kent State University Press (259 pp.; paper, \$18.00 U.S.).

Reviewed by Michael E. Lomax, University of Iowa.

The Philadelphia Phillies is a facsimile edition of the team's 1952 baseball season. Originally published by G. P. Putnam, the book is an addition to the Writing Sports Series, which publishes reprints of classic sports books and original manuscripts of literary quality. Frederick Lieb and Stan Baumgartner trace the Phillies's origins from the mid-nineteenth century to the lean years of the Great Depression, and highlight the 1950 pennant winning, when, with a group of young players known as the "Whiz Kids," it seemed as if the club would compete for the World Series championship for years to come.

Essentially, the book is a popular history, chronicling every year from the late nineteenth century to the 1952 season, when the Phillies finished fourth in the National League standings. Lieb, born in Philadelphia in 1888, followed the Phillies as a fan, and later as a writer for the Philadelphia News Bureau. In 1911, he moved to New York City, where he covered the Yankees for the New York Press, and later with other newspapers in Gotham, including the Post, the Morning Sun, and the Telegram. In 1935, Lieb joined the Sporting News as a regular columnist, and over the next 35 years he became one of the premier baseball writers of the first half of the twentieth century. In 1972, Lieb was inducted into the writers' wing of the Baseball Hall of Fame.

Lieb's collaborator, Stan Baumgartner, was a veteran sportswriter for the Philadelphia Inquirer and a former baseball player. Baumgartner pitched in the major leagues for eight seasons, five with the Phillies and three with the Athletics. In 1924, he posted a respectable 13-6 won-lost record as a member of the Athletics. His career record was 26-21, with 129 strikeouts, and a 3.70 earned run average. More important, Baumgartner brought with him the perspective of a former ballplayer in what was described as the "unforgiving culture of Philadelphia sports" (p. ix).

Scholars reading the book will find it lacking in context, somewhat understandable given the fact that it was first published in an era when sports books were written in an uncritical and sentimental manner. Nothing illustrates this better than the authors' treatment of Brooklyn Dodgers hall of famer Jackie Robinson. There was no mention of Robinson breaking baseball's color barrier in 1947, or the Phillies's deplorable treatment of the Dodgers second baseman during his first visit to Philadelphia. In essence, The Philadelphia Phillies reflected Lieb's devotion to his hometown Phillies and overall love of the game, whereas Baumgartner offered his unique insight as a former player and sportswriter.

\section{The Chicago Sports Reader: 100 Years of Sports in the Windy City}

Edited by Steven A. Riess and Gerald R. Gems. Published in 2009 by the University of Illinois Press (384 pp.; cloth, \$75.00 U.S. / paper, \$24.95 U.S.).

Reviewed by Philip C. Suchma, Lehman College CUNY, New York 
Chicago sport has been the source of lovable losers (the Cubs), global icons (Michael Jordan), and a pop culture phenomenon ('85 Bears "Super Bowl Shuffle"). The focus on professional sports, however, says nothing of the city's rich tapestry of prep, collegiate, and company sports teams; recreational and social influences; and prominent entrepreneurs. Chicago has been an important location not just for play, but also for innovation. It is an urban center in which sporting activities were nurtured and challenged to best address the needs and wants of an evolving community and nation.

Steven Riess and Gerald Gems, two of the foremost urban-sport scholars (as well as Chicagoland residents), have pulled together a diverse collection of studies on sport in the Second City and have shed light on the cultural impact it has had on the United States. The Chicago Sport Reader brings forth the city's broader sporting history and informs the reader of Chicago's importance since the late nineteenth century in establishing practices and institutions of recreation and sport. In the tradition of urban-sport monographs, the collection of essays presented here furthers the field of sport studies' understanding of the sport-city nexus as it is rooted within physical spaces and the individuals and communities that provide them with function and meaning through recreational and sporting activities.

Thirteen chapters, arranged chronologically, flesh out the place of sport within the thriving metropolis' culture. All but one of the examinations in this collection had been published previously (John Wong's examination of the origins of the Chicago Blackhawks being the exception), but they successfully work together here to present the qualities of modernizing sport. The chapters synthesize scholarship and story telling, making the diversity and development of urban sport in the Midwest accessible. The various authors make clear that Chicago was a thriving modern city where sport was fashioned, refashioned, and consumed in the customs of the area instead of merely being imported from the East Coast. Furthermore, this relationship between sporting spaces and communities reinforces the arguments on modernization put forth by Allen Guttmann in Ritual to Record, and has been a significant feature of the larger body of urban-sport scholarship.

The Reader's primary strength comes from the collection of History and Sport Studies scholars whose contributions tell the larger tale of the developing Midwestern metropolis. Robin Lester's and Dan Nathan's entries were taken from books that received the NASSH book award, and several of the authors have also received special scholarly recognition for their research.

Thematically, the examination of the business of sport and the entrepreneurial spirit underlies the entire collection. The collection begins with Riess discussing the tricky-but-necessary relationship between track owners and the Chicago political machine and ends with Walter LeFeber articulating the global influence of Michael Jordan as both sport and advertising icon. Studies by Cord Scott on the dedication and ingenuity of early automobile enthusiasts, by Michael Lomax on African-American entrepreneurs pursuing expanded opportunities in baseball in the early twentieth century, by John Wong on creating a culture to embrace and finance a new ice hockey venture in Chicago, and by Susan Cahn on defining and challenging traditional gender boundaries through women's professional baseball are among the excellent articles that stand out.

Concerns are few and minor. The New Immigrants had a lasting impact on the image of Chicago, yet their sporting cultures are only discussed in limited detail in the Introduction. There are also small gaps in continuity-a lack of introduction 
for some names and places, for example - that could confuse a reader unfamiliar with Chicago. In one instance, information in the brief introduction to Bushnell's contribution on the bicycle craze (chapter 2) conflicts with that of the article's text; the former saying that bicycles "were not cheap," whereas the latter states that they were "relatively inexpensive" only two pages later.

This study is valuable to both the casual and serious scholar. Readers with an interest in Chicago history will enjoy the descriptive manner in which defining moments and individuals from the city's sporting past have been captured. For more serious scholars, the Reader offers additional benefits. It furthers our understanding of the importance of the modern city in the development of modern sport. Building off that idea, we see the growth process taking place in the confines of the traditional American heartland rather than more prominently recognized urban centers of the East Coast. The book additionally addresses the multiple ways in which sport has influenced and has been influenced by distinct communities and cultures-whether divided along race and ethnicity, gender, or social class - in the metropolis. Finally, these brief but indispensable studies serve as introductory points for new and more elaborate dialogues. 